\title{
Neotypification of the Interspecific Hybrid Pterocarya $\times$ rehderiana (Juglandaceae) Originating at the Arnold Arboretum
}

\author{
Jared Rubinstein and Michael Dosmann \\ Arnold Arboretum of Harvard University, 125 Arborway, Jamaica Plain, Massachusetts 02130, U.S.A. \\ Author for correspondence: jrubinstein@fas.harvard.edu
}

Abstract. The interspecific hybrid Pterocarya $\times$ rehderiana C. K. Schneid. was first described in 1903 but there is no record of typification. A neotype is designated here from among the earliest collections of the nothospecies stored at the Herbarium of the Arnold Arboretum (A).

Key words: Alfred Rehder, Camillo Schneider, Juglandaceae.

Pterocarya $\times$ rehderiana C. K. Schneid. is a nothospecies originating from an interspecific cross between P. stenoptera C. DC. and P. fraxinifolia (Lam.) Spach that displays intermediate characteristics between its two parents (Schneider, 1906). The hybrid also grows more vigorously than its parents and appears to be more cold hardy (Rehder, 1947). Given the geographically distinct native ranges of the two parent species $(P$. stenoptera grows in East Asia, while P. fraxinifolia is native to the Caucasus), modern hybridization has likely only occurred under cultivation.

The first recorded observation of Pterocarya $\times$ rehderiana occurred at the Arnold Arboretum in 1903 in Boston, Massachusetts, when Alfred Rehder noted that trees labeled as P. stenoptera (Arnold Arboretum accessions 1191 and 16787) displayed characteristics of both $P$. stenoptera and $P$. fraxinifolia (Rehder, 1903). The trees in question were grown from seeds collected from a $P$. stenoptera at the Arboretum de Segrez outside of Paris by Pierre Alphonse Lavallée and sent to the Arnold Arboretum in 1879 and 1880 (Rehder, 1913). Rehder identified the trees as hybrids in 1903 (though without a proposed hybrid epithet), then apparently conferred with his friend and colleague Camillo K. Schneider in Vienna (Rehder, 1903). In 1904, Schneider published a description with a new epithet in the first volume of his Illustriertes Handbuch der Laubholzkunde based on plant material from the "Bastardes" growing in the Arnold Arboretum and sent to him by Rehder (Schneider, 1906).

In 2018, during a curatorial review of the Arnold Arboretum's Juglandaceae collection in preparation for the possible arrival of thousand cankers disease, a fungal/insect complex that affects Juglans L. and Pterocarya Kunth in North America, the authors observed that there is no published record of a type specimen designation for $P$. ×rehderiana. Schneider did not include a type designation in his 1904 description, nor did a literature search reveal any other publication after the fact. We reviewed the $P$. Xrehderiana specimens at the Harvard University Herbaria (including the Arnold Arboretum herbarium) from Rehder's and Schneider's era and did not find any annotations or notes indicating that any of the specimens were ever considered the type. Similarly, personal correspondence with the herbarium staffs at the Royal Botanic Gardens, Kew (Liz Brogan at K, pers. comm.), the Royal Botanic Garden Edinburgh (Hannah Atkins at E, pers. comm.), the Botanischer Garten und Botanisches Museum in Berlin (Robert Vogt at B, pers. comm.), the Naturhistorisches Museum in Vienna (Christian Bräuchler at W, pers. comm.), and the Muséum National d'Histoire Naturelle in Paris (Cécile Aupic at PC, pers. comm.) did not provide any further evidence of any specimen with annotations indicating it was a type specimen. It is possible that Schneider deposited a specimen of the nothospecies locally, at the predecessor of the Naturhistorisches Museum in Vienna where he apparently lived at the time, which would have been subsequently destroyed in July of 1945 (Stern, 1978; Bräuchler, pers. comm.).

Therefore, because a type specimen was never published, and no existing specimen includes any annotations indicating that it was considered a type by Schneider, an existing specimen in the Herbarium of the Arnold Arboretum collected in 1901 is designated here as the neotype for Pterocarya $\times$ rehderiana.

Pterocarya $\times$ rehderiana C. K. Schneid., Ill. Handb. Laubholzk 1: 93. 1904. TYPE: U.S.A. Massachusetts: Jamaica Plain, 1901, J. G. Jack s.n. (neotype, designated here, A [barcode] 00786582!). Figure 1.

Notes. The selected specimen was collected by John G. Jack in 1901 from a multi-tree accession (accession number 1191) growing in the Arnold Arboretum's Living Collection; however, the label does not indicate which exact tree within accession 1191 Jack vouchered. The specimen shows the key characteristics of the hybrid that differentiate it from its parents, namely 


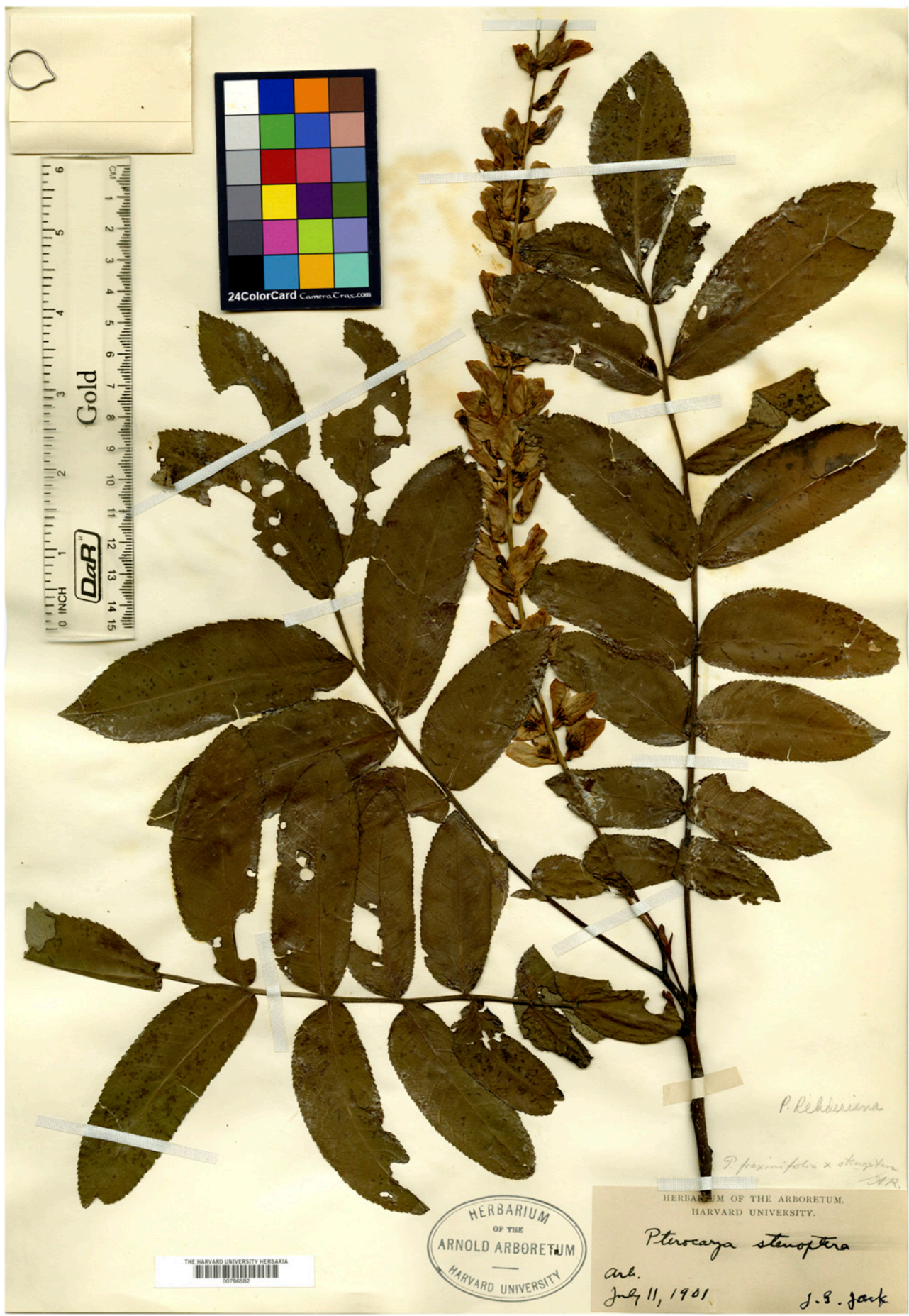

Figure 1. Neotype of Pterocarya $\times$ rehderiana C. K. Schneid. High-resolution scanned image taken at the Herbarium of the Arnold Arboretum (A, 2019). 
the narrowly winged rachis; narrow, acuminate, and coarsely serrate leaflets; and narrow, long wings in the fruit (Rehder, 1913). There are currently four living trees in accession 1191. In 1913, Rehder estimated the height of one of them at about $12 \mathrm{~m}$; the tallest today is almost $25 \mathrm{~m}$. One particularly striking specimen $\left(1191^{*} \mathrm{E}\right)$ has two massive leaders with DBHs of 103 and $102.5 \mathrm{~cm}$, respectively.

Acknowledgments. The authors thank Anthony Brach and Kanchi Gandhi at the Harvard University Herbaria, as well as the curatorial staffs at B, E, K, and PC, for their assistance with this project.

\section{Literature Cited}

Rehder, A. 1903. Pterocarya fraxinifolia $\times$ stenoptera (hybr. nov.). Mitt. Deutsch. Dendrol. Ges. 12: 116-117.

Rehder, A. 1913. Pterocarya rehderiana C. K. Schneid. Pp. 79-81 in C. S. Sargent (editor), Trees and Shrubs, vol. 2. Houghton, Mifflin and Company, Boston.

Rehder, A. 1947. Manual of Cultivated Trees and Shrubs Hardy in North America, Exclusive of the Subtropical and Warmer Temperate Regions, 2nd ed. Macmillan, New York.

Schneider, C. K. 1906. Illustriertes Handbuch der Laubholzkund, vol. I. Gustav Fisher, Jena.

Stern, L. S. 1978. Index Xylariorum. Institutional wood collections of the world. Taxon 27: 233-269. 